\title{
Numerical Analysis of the Cold Gas Dynamic Spray Surface Coating Process
}

\author{
Moonga Kando Hamiyanze ${ }^{1, a}$, Jen Tien-Chen ${ }^{1, b}$ \\ ${ }^{1}$ Department of Mechanical Engineering Science, University of Johannesburg, \\ Gauteng, 2006, South Africa

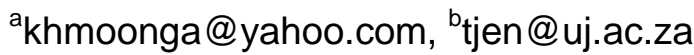

\section{Keywords: Cold Spray, Numerical Analysis, Multiple Particle Impact}

\begin{abstract}
In Cold Spray, bonding is formed between substrate and the particles and between particles by impact which causes material deformation and temperature rise. During impact process, plastic deformation and frictional interaction of materials generate heat and strains/stresses. In this paper, a numerical study on multiple particles deposition process show that the plastic equivalent strain (von misses stress) and the temperature values, compare to a single particle impact under same conditions, are higher in multiple particles compared to a single particle impact. Based on this observation, there is a possibility of the bonding mechanism for the whole film coating better explained using the multiple particles modeling than is predicted using single particle analysis However the actual impacting mechanism in the multiple particle interaction is not yet fully understood and still requires further investigation.
\end{abstract}

\section{Introduction}

Cold spray is a technology used to make coatings [1,2] where particles are accelerated to supersonic speed in a propellant gas usually helium or nitrogen. The accelerated particles deposit on a substrate and then bond to create a film. Up to now, there is a limited amount of data detailing the interaction of particle-particle and particle-substrate during the cold spray deposition process and in the entire film coating process.

Numerical analysis is a useful tool in understanding complex nonlinear dynamic process such as particles deposition on a substrate since precise calculations with analytical methods are essentially impossible. Investigations in such a process can be followed by experimental evidence. Though quite a few studies have been done in understanding the behavior of single particle deposition, cold spray is a multiple particles deposition process. Furthermore, the fundamental physics of multiple particles impact is not yet well understood. Because of the complexity of the multiple particles impact models, progress has been slow in numerical modeling of this process. In comparison, the single particle impact process has been studied in much more detail. Therefore, the development of comprehensive numerical models on real cold spray process (i.e., multiple particles deposition) is desired [3].

In this paper a simulation of the cold spray process in ABAQUS shows that the von misses plastic equivalent strain, (PEEQ) and the temperature, (TEMP) values are increased in multiple particles impact scenarios as compared to the impact of a single particle.

\section{Review on the Numerical data}

With the continuous development of cold spray technology, the several fronts on the study of cold spray are being undertaken by the research community. The computational modeling helps to build insight into the system characteristics on the cold spray. On the numerical simulations of cold spray, research has shown that for particle single impacts, the plastic equivalent strain increased with velocity. For instance, the numerical study done by Yu et al. [4] is shown in Fig. 1 for copper impact on a copper substrate. They found that temperature increases with the increase in impact 
velocity. However, the cold spray process is a multi-particle multi-dimensional complex system. Values obtained in single impact might not be fully representative of the entire coating process.

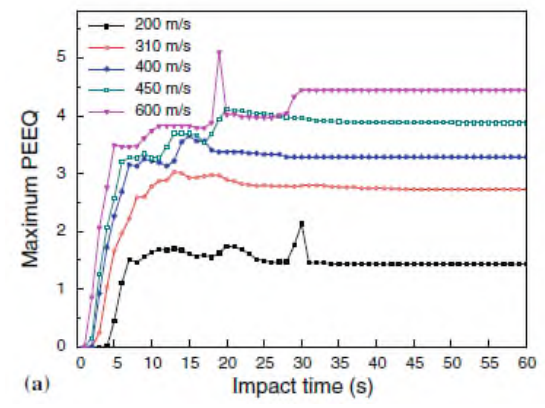

(a)Adiabatic analysis

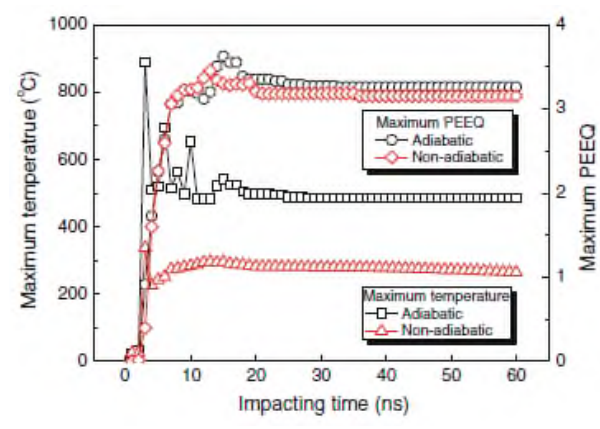

(b) Evolutions of maximum temperature and PEEQ at $400 \mathrm{~m} / \mathrm{s}$

Fig. 1 Numerical simulations of single particle impact of a $20 \mathrm{um} \mathrm{Cu}$ particle on $\mathrm{Cu}$ substrate $[4,7]$

So far from the data available it is not clear the differences that exist in single particle impact compared to multiple particles impact analysis. In order to further investigate this process, we performed a numerical simulation using a Lagrangian framework. The numerical parameters used for both single and multiple particle models were consistent in the simulation so that any difference in the results between the two models should be because of the multi-particle interaction.

\section{Finite Element Models}

A Lagrangian finite element ABAQUS CAE/Explicit model was setup with the mesh as shown in Fig. 2 in a coupled temp-displacement analysis. The substrate was anchored and supported at the base, and on the sides.

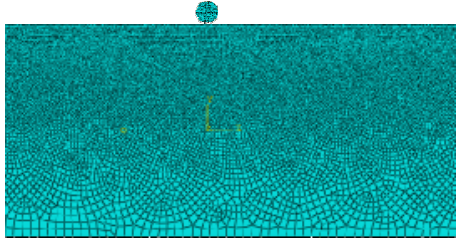

(a) Single Particle

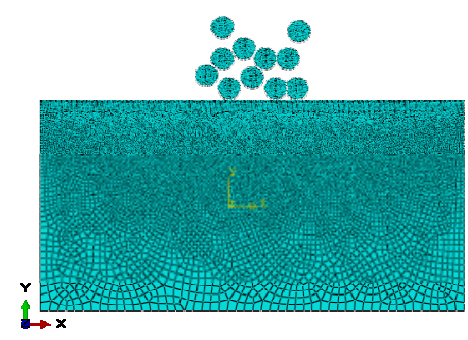

(b) Multiple Particles

Fig. 2 The computational models.

The Johnson cook model was used to define the material properties which are listed in Table 1 . The material properties for both single and multiple particle models were the same.

Table 1. Properties of copper and Aluminum.

\begin{tabular}{|c|c|c|}
\hline Material & $\mathbf{C u}$ & $\mathbf{A l}$ \\
\hline Density, & 8960 & 2710 \\
\hline Thermal Conductivity, $W /\left(\mathrm{m}^{\circ} \mathrm{C}\right)$ & 386 & 220 \\
\hline Specific Heat Capacity, & 383 & 920 \\
\hline Melting Point, ${ }^{\circ} \mathrm{C}$ & 1083 & 643 \\
\hline Thermal Expansion, $/ 1^{\circ} \mathrm{C}$ & 0.00005 & \\
\hline Elastic Modulus, $\quad$ GPa & 124 & 65.762 \\
\hline Poisson's ratio & 0.34 & 0.3 \\
\hline JC Plasticity: $A, \mathrm{MPa}, B, \mathrm{MPa}, n, C, m$ & $90,292,0.31,0.025,1.09$ & $148.361,345.513,0.183,0.001,0.859$ \\
\hline JC Damage: d1, d2, d3, d4, d5 & $0.54,4.89,-3.03,0.014,1.12$ & $0.071,1.248,-1.142,0.147,1$ \\
\hline Reference Temperature, ${ }^{\circ} \mathrm{C}$ & 25 & 25 \\
\hline Reference Strain, $1 / s$ & 1 & 1 \\
\hline
\end{tabular}


According to the Johnson cook model the yield flow stress, $\bar{\sigma}$, of the material is expressed as follows

$$
\bar{\sigma}=\left[\mathrm{A}+\mathrm{B}\left(\overline{\bar{\varepsilon}}^{\mathrm{pl}}\right)^{\mathrm{n}}\right]\left[1+\mathrm{C} \ln \left(\frac{\dot{\bar{\varepsilon}}^{\mathrm{pl}}}{\dot{\varepsilon}_{0}}\right)\right]\left(1-\hat{\theta}^{\mathrm{m}}\right)
$$

where, A, B, n, C, and $\mathrm{m}$ are material-related constants, $\bar{\varepsilon}_{p}$ is the effective plastic strain, ${ }^{{ }^{p l}}{ }^{p l}$ is the strain rate, $\varepsilon_{b}$ is the reference strain rate, $\tilde{\theta}$ is the nondimensional temperature defined as follows:

$$
\hat{\theta} \equiv\left\{\begin{array}{cl}
0 & \text { for } \mathrm{T}_{\text {transition }} \leq \mathrm{T} \leq \mathrm{T}_{\text {melt }} \\
\frac{\left(\mathrm{T}-\mathrm{T}_{\text {transition }}\right)}{\left(\mathrm{T}_{\text {melt }}-\mathrm{T}_{\text {transition }}\right)} & \text { for } \mathrm{T}<\mathrm{T}_{\text {transition }} \\
1 & \text { for } \mathrm{T}>\mathrm{T}_{\text {melt }}
\end{array}\right.
$$

where, $T$ is the current temperature, $T_{\text {melt }}$ is the melting temperature, and $T_{\text {tronsition }}$ is the transition temperature defined as the one at or below which there is no temperature dependence on the resultant yield stress.

In this simulation, the impact velocity was set to $500 \mathrm{~m} / \mathrm{s}$, the initial temperature of both the substrate and the particles were 25 degrees Celsius and the particle diameter was $10 \mu \mathrm{m}$ copper, while the substrate was defined with aluminum material properties. CPE4RT elements were used in the mesh, which is a 4-node plane strain thermally coupled quadrilateral. The mesh resolution was $1 / 40$ diameter of the particles.

\section{Simulation Results}

The results of the numerical simulation are shown on Fig. 3 for both the single particle impact (Fig. 3 (a)) and the multiple particle impact (Fig. 3 (b)).

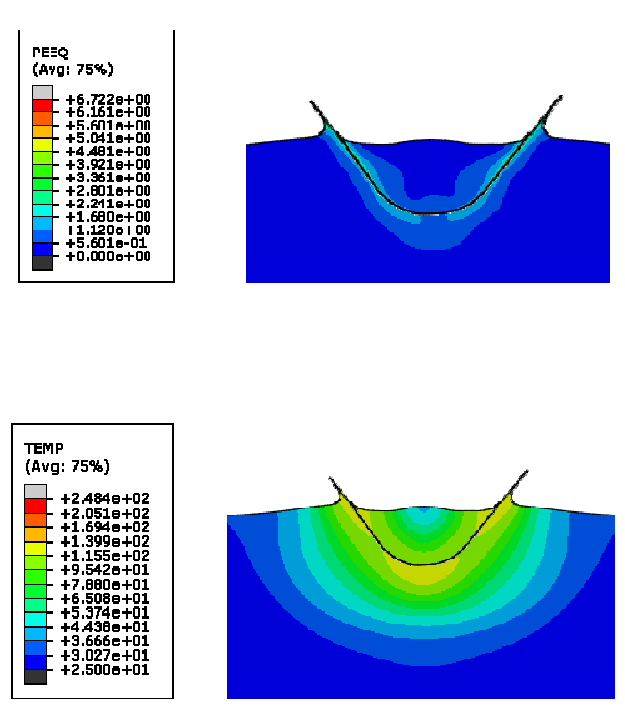

(a) Single Particle impact (38ns after impact)

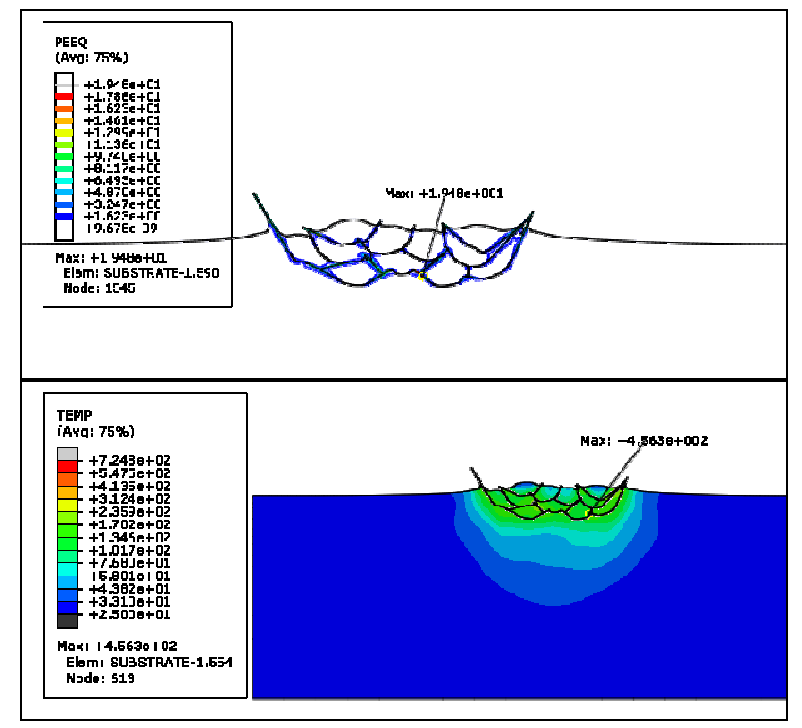

(b) Multiple particle impact (63.3ns after impact)

Fig. 3 The simulation results (temperature is given on a log scale).

Our results show the plastic equivalent strain value of 6.72 for single impact and 19.48 for multiple particle impact of copper on aluminum substrate at $500 \mathrm{~m} / \mathrm{s}$. The Maximum temperature was 248.4 degrees Celsius on the single impact and 724.8 degrees Celsius on multiple impacts. The multiple impact values are higher than that observed in a single particle in our models implying that the multiple particle impact scenarios generate much more plasticity and heat as opposed to a single particle.

Similar trends can be observed in Li et al. [5] using Eulerian model on both single particle and 
multiple particles as shown in Fig. 4. For instance, at $500 \mathrm{~m} / \mathrm{s}$ the plastic strain values are observed to be 4.04 for $\mathrm{Cu}$ particle on $\mathrm{Cu}$ substrate and 5.95 for $\mathrm{Cu}$ particle on $\mathrm{Al}$ substrate for single particle impact as shown in Fig. 4 (a)(1), (2). Whereas in Fig. 4 (b)(1),(2) at $600 \mathrm{~m} / \mathrm{s}$ velocity the PEEQ values are 4.23 for a $\mathrm{Cu}$ particle on a $\mathrm{Cu}$ substrate and 6.42 for a $\mathrm{Cu}$ particle on $\mathrm{Al}$ substrate, respectively. In the case of multiple particles impact for $\mathrm{Cu}$ particles on $\mathrm{Cu}$ substrate, the PEEQ strain was 6.14 (Fig. 4(a)(3)) and 7.52 (Fig. 4(b)(3)) for $500 \mathrm{~m} / \mathrm{s}$ and $600 \mathrm{~m} / \mathrm{s}$ respectively. It is worth noting that we noticed an increase of the plastic strain from 4.04 in single particle impact to 6.14 in the multiple particles impact case at $500 \mathrm{~m} / \mathrm{s}$. Similarly, for $600 \mathrm{~m} / \mathrm{s}$ velocities the plastic strain increased from 4.23 single particle impacts to 7.52 multiple particles impact, showing an increased PEEQ value in multiple particles as compared to a single $\mathrm{Cu}$ particle impacting on a $\mathrm{Cu}$ substrate.
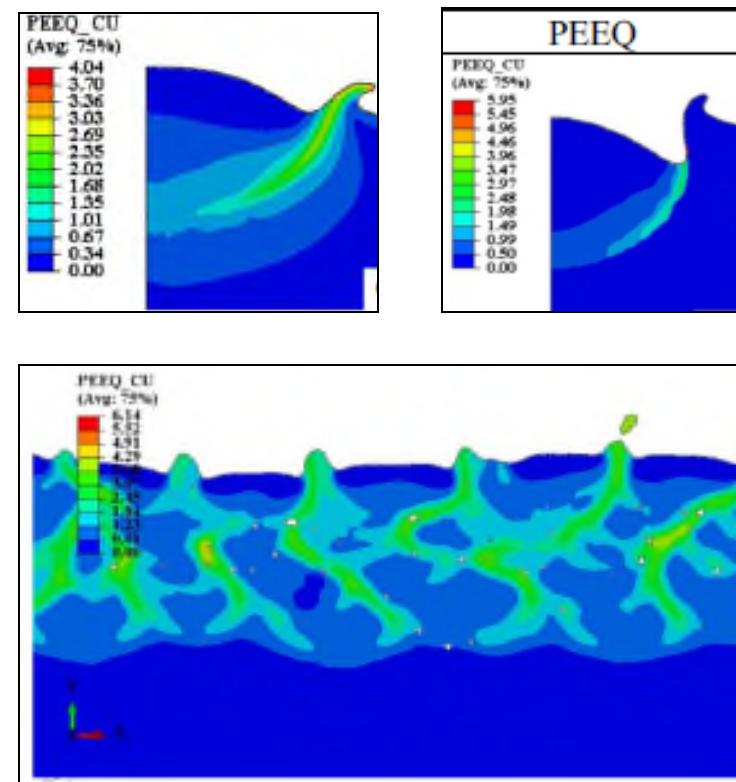

a) PEEQ at $500 \mathrm{~m} / \mathrm{s}:(1) \mathrm{Cu} / \mathrm{Cu}$ and (2) $\mathrm{Cu} / \mathrm{Al}$ single impacts; (3) Multiple impacts $\mathrm{Cu} / \mathrm{Cu}$
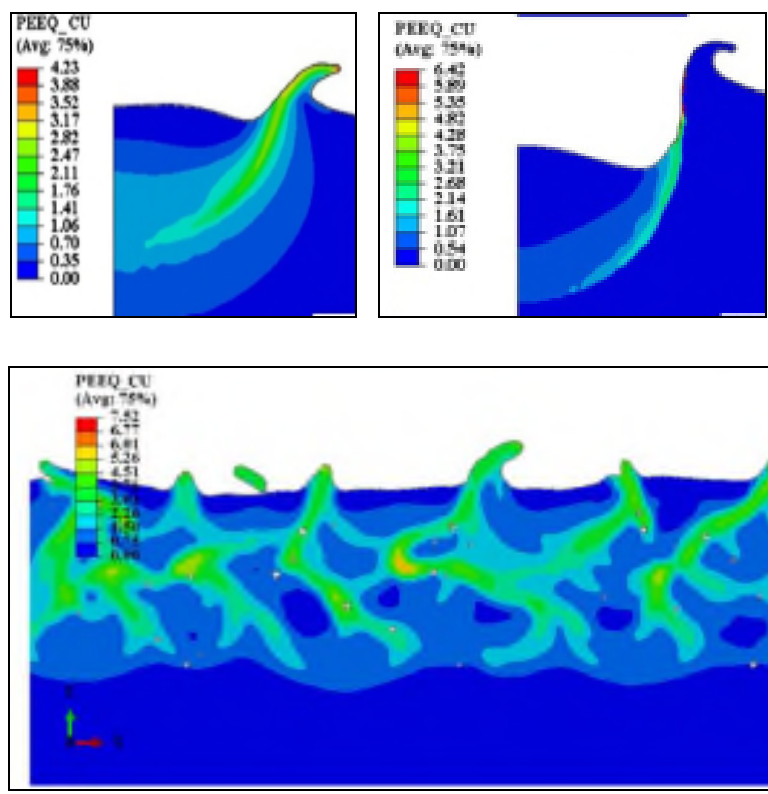

(b) PEEQ at 600m/s: (1) $\mathrm{Cu} / \mathrm{Cu}$ and (2) $\mathrm{Cu} / \mathrm{Al}$ single impacts; (3) Multiple impacts $\mathrm{Cu} / \mathrm{Cu}$

Fig. 4 Numerical Simulations of particle impacts of $\mathrm{Cu}$ on $\mathrm{Cu}$ and $\mathrm{Cu}$ on $\mathrm{Al}$ [5].

It is not yet known whether this phenomenon is independent of either adiabatic or non-adiabatic assumption in the numerical analysis.

Yu et al. [4], Li et al [6] and Wang et al. [7] studied the effects of impact velocity on the steady maximum PEEQ in adiabatic and on non-adiabatic conditions for several pairs of materials on single particle impact (Fig. 5). It is seen from the Fig. 5 that the PEEQ values from $200 \mathrm{~m} / \mathrm{s}$ to $700 \mathrm{~m} / \mathrm{s}$ were all less than 5.0 for both cases in their study. This might be indicative that this phenomenon is true for both cases.

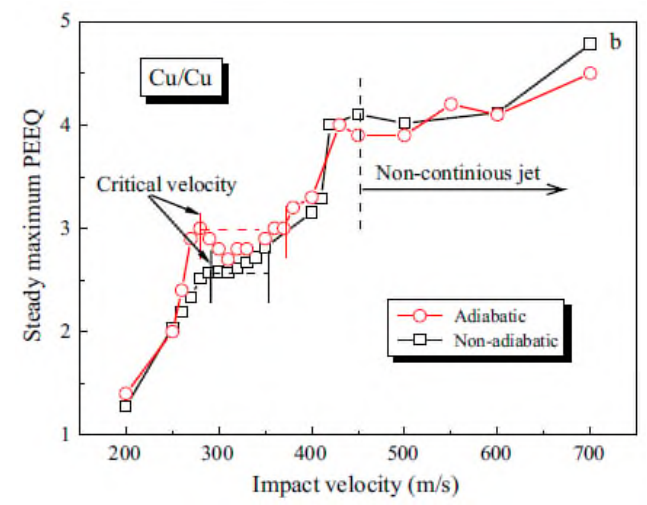

(a) Single impact Adiabatic and non adiabatic

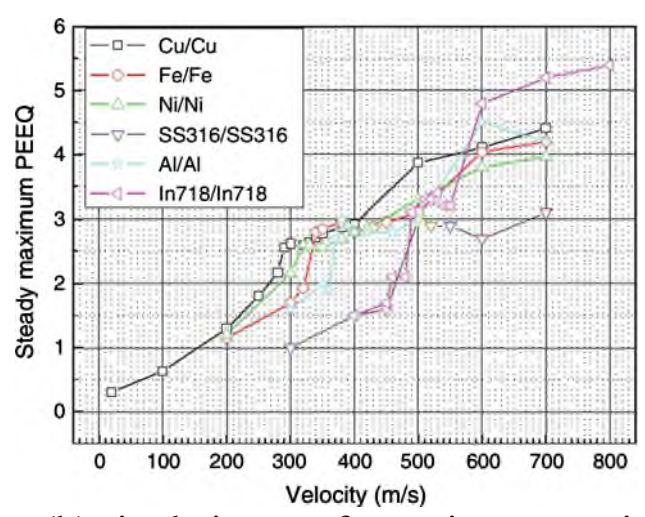

(b) single impact for various materials

Fig. 5 Effect of Impact Velocity on the steady maximum PEEQ [4, 6, 7]. 
In addition, though the increase in plastic equivalent strain and temperature can be attributed to increased stresses, the actual impacting mechanism is not yet fully understood and requires further investigation.

\section{Conclusion}

In the numerical analysis, it was observed that the plastic equivalent strain and particle/substrate temperature increased in multiple particles as compared to a single particle under same conditions. Based on this observation, there is a possibility of the bonding mechanism for the entire film coating process could be better explained using the multiple particles than predicted using single particle analysis.

\section{References}

[1] Y. V. Kurochkin, Y. N. Demin, S. I. Soldatenkov. Demonstration of the method of cold gas dynamic spraying of coatings. Chem. Petrol. Eng. 38(3) (2002) 245-248.

[2] A. P. Alkhimov, S. V. Klinkov, V. F. Kosarev. Experimental study of deformation and attachment of microparticles to an obstacle upon high-rate impact. J. Appl. Mech. Tech. Phys. 41(2) (2000) 245-250.

[3] K. H. Moonga, T. C. Jen. Theoretical and Computational Models for Cold Spray of Functional Thin Films. J. Therm. Spray Tech. Special Issue on Cold Spray, 2017 (to appear)

[4] M. Yu, W. Y. Li, F. F. Wang, H. L. Liao. Finite element simulation of impacting behavior of particles in cold spraying by Eulerian approach. J. Therm. Spray Tech. 21(3-4) (2012) 745-752.

[5] W. Li, K. Yang, D. Zhang, X. Zhou. Residual stress analysis of cold-sprayed copper coatings by numerical simulation. J. Therm. Spray Tech. 25(1-2) (2016) 131-142.

[6] W. Y. Li, M. Yu, F. F. Wang, S. Yin, H. L. Liao. A generalized critical velocity window based on material property for cold spraying by Eulerian method. J. Therm. Spray Tech. 23(3) (2014) $557-566$.

[7] F. F. Wang, W. Y. Li, M. Yu, H. L. Liao. Prediction of critical velocity during cold spraying based on a coupled thermomechanical Eulerian model. J. Therm. Spray Tech. 23(1-2) (2014) 60-67. 